\title{
The Degree of Openness of Undergraduate Education to Contemporary Art
}

\author{
Ana Maria Aprotosoaie-Iftimi \\ Teacher Training Department, George Enescu National University of Arts, Iaşi, Romania \\ Email: anamariaiftimi@gmail.com
}

How to cite this paper: AprotosoaieIftimi, A. M. (2019). The Degree of Openness of Undergraduate Education to Contemporary Art. Psychology, 10, 1125-1142 https://doi.org/10.4236/psych.2019.108073

Received: May 22, 2019

Accepted: June 27, 2019

Published: June 30, 2019

Copyright $\odot 2019$ by author(s) and Scientific Research Publishing Inc. This work is licensed under the Creative Commons Attribution International License (CC BY 4.0).

http://creativecommons.org/licenses/by/4.0/

\section{c) (i) Open Access}

\begin{abstract}
We live today in a complex, ever changing world, with a wealth of scientific and technological discoveries, along with a great variety of artistic events; a world in which new concepts are emerging that try to define the condition of contemporary man. As a consequence, previously known parameters change; new terms are emerging, determined by the reality of the new times, globalization-driven reality, the diminishing - tending towards disappearance-of the boundaries between culture and subculture and the predominance of the visual. Inevitably, the educational act is influenced by these phenomena. The extent to which education in the artistic sphere is open to understanding these changes will determine the growth and development of people capable of adapting to new social and cultural-artistic realities. Without minimizing the values and results of the teaching experience, it is clear that the younger generation of teachers has a much more flexible approach, even though curriculum documents often operate in fixed frames.
\end{abstract}

\section{Keywords}

Visual Art Education, Artistic Culture, Teaching Experience, Art Curriculum

\section{Conceptual Delimitations}

The term art can refer to several aspects, such as: the result of creative abilities; a process that calls for specific artistic skills; the total works of art; the product of interdisciplinary activities, etc. In general, art can be spoken of as a special field, an essential component of culture, the result of fundamental human spiritual needs capable of provoking certain reactions, states, emotional and cognitive experiences.

Throughout the history of culture, attempts to define art and to describe the nature of art have been numerous. Artworks can be interpreted as means of ex- 
citement, a way of appreciating the formal elements by themselves and as representation or mimesis, a term derived from Antiquity, from the Greek thinker Aristotle. The philosopher Richard Wollheim (1923-2003) affirms that the nature of art is "one of the most elusive basic issues of human culture" (Wollheim, 1980) and Goethe defines art as another representation, a second nature. Russian writer Lev Tolstoy identifies art as an indirect means of communicating from one person to another, calling it "expressing and communicating these feelings" (Tolstoy apud. Levinson, 2003) with reference to superior moral feelings. The aesthetician Benedetto Croce advances the idea that art produces emotions (Croce apud Levinson, 2003), and R.G. Collingwood (1889-1943), the English philosopher, states that the work of art already exists in the mind of the creator (Collingwood apud. Wollheim, 1980). If some more recent aestheticians and philosophers interpret art as a way in which a community develops an environment of interpretation and self-expression, the American philosopher George Dickie (1926-) is known to be one of the partisans of the "institutional" theory of art, a theory that defines artwork as any object, artifact to which a qualified person (or institution) conferred the "status of candidate to appreciation" (Dickie apud. Kennick, 1979). Defining art and establishing its role have become two problematic issues since the 20th century. Thus, philosopher Richard Wollheim distinguishes three ways of analyzing the aesthetic value of art: the realistic position, where the aesthetic quality has an absolute value, independent of the individual's conception; the objectivist position, where the aesthetic quality is also an absolute value, but it is dependent on the human experience and the relativist position; the situation in which the aesthetic quality is not an absolute value, but it depends on and varies together with human experience (Wollheim, 1980). In this respect, Clement Greenberg (1909-1994), essayist and art critic, states in an article published in 1980 referring to the art of the 1960s, that "the essence of modernism lies in [...] using the methods characteristic of a discipline to characterize the discipline itself, not for subversive purposes, but to strengthen its area of competence" (Greenberg, 1982), a definition which is of particular importance for many ideas of the various artistic movements of the twentieth century and the beginning of the 21st century. Pop and Pop artists such as Andy Warhol are known for their criticism of mass culture and of arts in general, criticism (and self-criticism) becoming some of the methods touched by artists of the 1980s, 1990s, 2000, a vision typical of most styles of the end of the 20th century period.

The Art of the last century and of the beginning of the $21^{\text {st }}$ Century is an art of unlimited exploration, new configuration frameworks are sought, each artistic manifestation being replaced or repressed by another, in a very short time. As, in each period, art is a manifestation of the characteristics reflecting the culture of the era to which the specificity of the society belongs to, the aspects that most influenced the art of this period are the increase of the global interaction and modernism, which, in philosophical essence, seek the idealistic way of represen- 
ting the truth, and makes place, after the second half of the twentieth century, to the quest for the impossible. Relativism is accepted as an inevitable truth, while culture and history are perceived as changing forms. The philosopher Theodor Adorno states that "it is clear that nothing art-related is obvious either by itself or art itself, nor its relation to the world, to the whole, not even art's right to exist. The loss of what what can be done spontaneously or unproblematically can not be compensated by the infinite opening of the new possibilities that reflection faces" (Adorno, 1998).

The term contemporary means the most current modes of expression and existence of the era, expressing the "spirit of the time" (Bartos, 2005) presently determined by scientific development and the evolution of society. First, the term "contemporary" overlapped or coincided with "modern". Since the Renaissance, the term "modern" has always been refreshed, with new meanings every time. Thus, "the meaning of the term contemporary depends on how long the phenomenon of modernity lasts as unity and homogeneity; currently, the contemporary present represents a maximum period of about a century or a minimum period of about 25 - 35 years" (Bartos, 2006). The extended meaning refers to the contemporary art that concerns the art of the entire 20th century, and the narrow meaning refers to the second half of the $20^{\text {th }}$ century, more precisely the period after the sixth decade, which coincided with the beginnings of postmodern art. Currently, modern art means the period between 1900 and 1960, the sixth decade perhaps being the maximum point for the development of modern art, the birth of postmodern art being dated by various art critics after 1960 or even after 1970.

Contemporary art appears as an ensemble of tendencies and styles representing the aesthetics of time, an evolutionary stage of constant transformation, of transition to new discoveries with an obvious experimental-exploratory character, contigurating postmodern art, as it precedes the new styles and trends of the $21^{\text {st }}$ century art. With general reference to the $20^{\text {th }}$ century art, contemporary artist Jenö Bartos states that "maybe for the twentieth century the most significant discovery about the knowledge of the universe was the specification of our inner and outer boundaries and the discovery of the relativity of the reference systems" (Bartos, 2006); Albert Einstein's theory of relativity as well as other scientific theories, profoundly changing the general way of approaching reality and having a strong impact on visual art as well. The modern concept of the ephemeral ideal substituted the classic and stable ideal of beauty. Moreover, by the end of the $20^{\text {th }}$ century, the very value and durability of modern art are challenged, due to concerns about media implications in social visual. Thus, contemporary disputes call into question the nature of postmodernism: is this a stage of modernism fulfillment, or is it a new art, the beginning of which coincides with the very beginning of the $21^{\text {st }}$ century and which could either determin re-naming the art of the twentieth century, or the re-signification of the terms modern modernism, modernity? Skeptics went further, wondering whether 
after modern art we could still talk about art. Thus, a crisis of art was evoked and the thesis of the death of art (after Hegel) was discussed again. In his turn, philosopher C. Castoriadis (1922-1997) proposes a mental experiment, for identifying with the values of the past, which, if followed, would seriously challenge contemporary artists and theorists who are confident in the future and vitality of the art between the two millennia. The philosopher uses terms such as ineptitude, proatitude, futility and intellectual dishonesty, hypercivilized and neo-illiterate public, defining our era as a "comic age of excrement, no-excrements fertilize the earth, the products of this age pollute it and make it sterile", and "contemporary culture is, at first expression, null” (Castoriadis apud. Zaharia, 1999).

In every field and in any historical period, and especially during the transition period, dual phenomena coexisted in antinomical opposition. Only time established the resistance of some of them, leading to the understanding, acceptance and assimilation of the culture, until the next stage, when the process was resumed. In the art of the present time, forms of the past coexist with new stylistic manifestations, which often may appear unconvincing, but which should not be analyzed "from the perspective of an aesthetics marked by the artistic creation of the already outdated age" (Zaharia, 1999). Starting from Brâncuşi's statement"better be wrong than stiff" (Zaharia, 1999), accepting stylistic diversity, apparently chaotic aesthetic tendencies, can be accepted more easily. At the same time, the perspective suggested by the art critic D.N. Zaharia, according to which the post vanguard draws in, by principle the reconnection of the creation to the values of the tradition of any past era, which may cause not only situations of stylistic divergence, but also the legitimate instauration of an eclectic style" (Zaharia, 1999). Contemporary visual artist Jeno Bartoş sums up the above statements, distinguishing in the present mural art two important directions but which could be extrapolated to art in general: "the continuation of the traditional line, but under the influence of new aesthetic concepts" would constitute the first orientation, and the second orientation, still at the beginning of its road, is "geared towards capitalizing on the latest technologies of visual communications and other inventions adaptable to visual arts." (Bartos, 2006).

\section{Creative Mediation Project: Contemporary Art (For Young People)}

Between the traditional form of education and other forms of educational manifestations of society, there are various forms of cultivation for young people, like the action of the educational platform (Babias \& Nollert, 2007) of the "Vector" Cultural Association in Iași, nominating the event Periferic 8-Art as Gift, in the framework of the Biennial of Contemporary Art held in Iași, in collaboration with the "George Enescu" Art University of Iași, from 3 to 18 October 2008.

The theme of the biennial consisted in proposing an alternative exchange model: "offering gifts, that is, the exchange it involves" (Onofrei, 2008b). In the market economy, as a planned exchange system, goods and services are offered 
following a clear agreement (Onofrei, 2008a); while the gift economy is an opposite system that works without an explicit agreement and it requires "free exchange, free cultural movement, "slow culture" (Osten, Szpilmann, Swieckowska, \& Szreder, 2009). Thus the Periferic 8 Biennial had "three major coordinates: art as an alternative economic system, the exchange relationship between art and the public and the local context of Iaşi, which imparts a type of social practice" (Vica, 2008).

The event initiated an open and complex dialogue between different fields, such as education and the fields of human creation (Bamford, 2006). Alternative models of education have been developed, in which artists, critics, theoreticians, pedagogues were involved, models oriented towards different age ranges-pupils, students, adults. Within these types of manifestations of alternative education models, other creative mediation projects were developed, of which we selected the Contemporary Art for Youth event, a project addressed to young high school students, with the stated aim of forming future artists open to the manifestations of contemporary art, as well as of forming a new, cultivated public, which we will describe in detail below.

The stated goal of the project was to stimulate the interest of a young public under full training in contemporary art, especially by focusing on high school students. The general objective was to investigate the extent to which art can be regarded as "gift" by young people, which was intended to be a starting point in creating a platform of creative reflection on contemporary art, elaborated and developed by adolescents, thus:

The objectives were: facilitating access to contemporary art in general, encouraging students to engage creatively in developing the concept of Art as a gift, responsiveness due to mediated contact with various types of contemporary art approaches. The targeted target group was represented by students from different high school education institutions in Iași, with cultural and artistic interests.

If about 50 students attended the mediation workshops, afterwards their number decreased. However, their gain is higher, because they received more information than those who have only attended classroom presentations. The mediation workshops were ended by the students' realization of 6 artistic projects, exhibited at "George Enescu" Art University in Iași.

The guided tour program was an appreciated end to the Contemporary art for young people mediation project. Guided tours to the four locations were organized by high school students each day of the biennial, locations where curators or organizers made it possible to go through the works in a language accessible to the students. It was estimated that there were between 150 and 200 students visiting the exhibitions, which was encouraging given the previous editions, where pupils did not attend at all. Although the openness of pre-university teachers has not always been in line with expectations, the interest shown by students reflects the possibility of continuing the idea of approaching and in- 
volving students from Iași in this type of contemporary art projects.

In terms of investigating the interest of young students in contemporary art, a follow-up was organized to see the impact of the stages of the project-media coverage, mediation, guided visits. Free discussions were held with students and teachers on the reception of the artistic events, and in the end different reactions were recorded, from both adults and young people, from a total lack of understanding, manifested by rejection, to enthusiasm and adhesion.

All the experience gained in the creative mediation project raised questions that, in their turn outlined areas of research on the degree of openness of the Romanian education system towards contemporary art (the opportunity to approach contemporary art themes in schools; the extent to which the school curriculum provides content and competencies in the direction of contemporary art; teachers' training; the existence of didactic materials covering the area of contemporary art; the usefulness and the necessity of developing students' skills in the field of contemporary visual art). These directions were addressed by a study: the situation of pre-university art education.

\section{The Degree of Openness of Undergraduate Education to Contemporary Art}

\subsection{Plan of Research and Its Deployment}

The objective of this research was the elaboration of a program to investigate the extent to which the pre-university education of Iași art appears open to the new formulas of contemporary visual expression. The research aimed to establish data that would allow the orientation of the educational practices at the pre-university level in the direction of approaching the activities that would use examples of contemporary art as work support; to ensure the possible improvement of educational practices at the university level in order to train teachers with a flexible vision in the curricular approach of the educational and artistic activities.

Hypotheses according to the opinion of the majority of the teachers in the Romanian pre-university education are:

- contemporary artists are oriented towards modern and postmodern art;

- the present curricula can develop students' visual creativity;

- the art curriculum is more oriented towards modern art language;

- school curriculum has a lower degree of flexibility in addressing contemporary art issues;

- it is considered to a small extent that contemporary art develops visual creativity as well as general creativity of students, both in secondary school and high school;

Dependent variables:

- Respecting the school program's curriculum determines the development of visual-plastic creativity - the extent to which it was considered that the current school curriculum of the Plastic Education discipline provides the formation of all the necessary competences that determine the visual creativity 
of the students;

- Curricular orientation-the direction in which the current artistic curriculum was considered to be oriented: towards a modern artistic language or towards the approach a contemporary artistic language;

- Formally, the use of contemporary examples is allowed or facilitated-the extent to which, at a formal level (educational policy makers and the ones involved in the implementation of these policies-the Ministry of Education, school inspectorates, heads of school institutions, and methodologists), the use of support materials inspired by contemporary art for the development of specific competences and the content of the curriculum was encouraged or facilitated;

- The developement of visual-plastic creativity through examples of contemporary art-the level at which the participants considered that visual creativity could be developed through examples of contemporary art used during didactic activities;

- The development of general creativity through examples from contemporary art-the level at which the participants considered that general creativity can be developed through examples of contemporary art used during didactic activities;

- The openness to the use of contemporary examples in didactic activities-the extent to which subjects have used examples of contemporary art in visual-plastic education classes on their own initiative;

Independent variables:

- Professional status - the quality of being a student in the third year of study or the quality of being a teacher-employee of a pre-university education institution;

- Level of experience-sharing the years of teaching experience according to the years of experience in education criterion, therefore: the student in the third year of study has completed two semesters of artistic pedagogical practice in a school education institution and has been considered a year of experience; the debut teacher has accumulated up to four years of experience; the experienced teacher has accumulated more than five years of experience;

- School profile-the predominant direction of student competences training in the educational units where the respondents gained the experience and which was represented by the vocational profile (the development of artistic skills) and the theoretical profile (general skills development).

- Level of school cycle-the school level of the surveyed respondents, based on the experience gained during the teaching career. Thus, there were both teachers and students who gained only secondary school experience, and there were teachers and students who gained both high school and secondary school level experience.

- Learning school cycle-the secondary school (childrens from 11 to 15 years old) and highschool learning cycle (childrens from 15 to 19 years old) at 
which the dependent research variables were reported to.

\subsubsection{Participants}

The research on the degree of openness of the education in Iași to the new visual expression formulas of contemporary art took place during the 2014-2015 school year, on a number of 68 subjects, debutant teachers, experienced teachers and future teachers-students the third year of the Faculty of Visual Arts and Design of the "George Enescu" University of Arts in Iași, which, along with the bachelor studies, followed the courses of the didactic training module of the Department of Teaching Staff Training (DPPD) of the same university.

\subsubsection{Instruments and Experimental Procedure}

A questionnaire containing 11 items was used in the present study.

Items 1, 2 and 3 referred to the current situation in the Romanian pre-university education, during secondary school and high school, in the field of arst. Item 1 measured the extent to which subjects considered that the current school curriculum for Plastic Education provided for the development of all competencies that determine the visual creativity of pupils. Item 3 measured the participants' opinion on the extent to which examples inspired by contemporary art was allowed and encouraged in school teaching activity. Items 1 and 3 were measured on a Lickert scale from 1 to 5 , where 1 means very small and 5 means very high. Item 2 measured the view of the direction in which the learning content, related to visual-artistic disciplines, is oriented towards a modern language or a contemporary language. The modern orientation was given a 1 , and the contemporary orientation was given a 2 in the statistical processing of the data.

Items 4 and 5 measured the extent to which subjects considered that the use of examples from contemporary art during arts activities in school could develop students' visual creativity (item 4) and overall student creativity (item 5). Items 4 and 5 were used to measure on a Lickert scale from 1 to 5 , where 1 means very little, and 5 means a lot.

Items 6,7 and 8 considered how open were the participants to use a contemporary artistic language both as teachers and as artists. Item 6 measured the subjects "perception of the frequency with which they used examples of contemporary art during their teaching experience, and item 7 measured the subjects" perception of the need to develop support materials containing contemporary art language. Items 6 and 7 were measured on a Lickert scale from 1 to 5, where 1 means very small or very little, and 5 means very large or very large. Item 8 measured the participants' perception of their own artistic orientation as rather oriented towards a modern language, or rather to a contemporary language. There were some subjects who chose both options. In the statistical processing, the "rather modern" answer was given an 1, the "rather contemporary" answer was given a 2, and the "both" answer was given a 3 .

Items 9,10 and 11 were demographic items, which gathered data on: the profile of the school institution where the subjects accumulated most years of expe- 
rience (vocational or general theoretical (item 9)), the level of the school cycle at which the subjects gained most experience (at gymnasium or high school level) (item 10), the years of experience (item 11). For statistical processing, in item 9, vocational schools received an 1, general theoretical schoolswas awarded for grade 1 and for grade 2 was given, item 10 for gymnasium received a 2; in item 10 , secondary schools received an 1 , highschools received a 2 . As far as item 11 is concerned, the number of years of experience was recorded. At the same time, the level of experience was taken into account; so, one year of experience was considered for the students, 4 years of experience for first-time teachers, and from 5 years of experience upward for experienced teachers. In the statistical processing of the data the following grades were given: 1 for students, 2 for first-time teachers and 3 for experienced teachers.

\subsection{Pre-University Art Education Situation: Correlative Study}

The study investigated the perception of pre-university education teachers regarding the current curriculum for Plastic Education, from the perspective of visual creativity and general creativity, by focusing on contemporary art and curricular flexibility with the purpose of improving the efficiency of artistic education.

Hypothesis No. 1. Development of visual-plastic creativity according to the learning cycle.

There are differences depending on the stage of learning regarding the opinion of the subjects related to the extent to which the curriculum determines the development of the visual-plastic creativity, meaning that the curriculum determines more the development of the visual-plastic creativity during the secondary school learning stage than at high school.

To verify this hypothesis, we applied the $t$ test for two pair samples. There are statistically significant differences [ $\mathrm{t}(68)=6.279, p=0.000$ ] between environments. According to the obtained results, the whole experimental group considered that the current School Curriculum develops to significantly more large extent visually-plastic creativity in secondary school students (the average is 3.67) compared to the students at high school (the average is 2.32).

Hypothesis No. 2. Development of visual-plastic creativity according to the profile of the school.

There are differences depending on the school profile regarding the opinion on how the curriculum determines the students' visual-plastic creativity, meaning that the subjects from the vocational profile consider more than the subjects from the theoretical profile that the school curriculum determines the development of visual-plastic creativity in both secondary school and high school students.

In order to verify this hypothesis, the $t$ test for two independent samples was applied. It was found that there are statistically significant differences in the threshold $p=0.001$ between the average of the subjects working in a vocational 
school institution and the subjects working in a theoretical school institution regarding the opinion on how the curriculum determines the development of creativity of secondary school student $[\mathrm{t}(68)=0.69, p=0.001]$, as well as that of high school students $[\mathrm{t}(68)=2.61, p=0.000] \mathrm{cf}$. Subjects working in vocational school institutions considered, more than the subjects who worked or who gained experience in theoretical profile institutions, that following the curriculum for the Plastic Education discipline determines the development of plastic visual creativity, both at secondary school as well as at the high school stage.

Hypothesis No. 3. The development of visual-plastic creativity according to the school stage level.

There are differences depending on the level of the school stage regarding the opinion on how the curriculum determines the development of students' visual-plastic creativity.

Sub-hypothesis No. 3 (a).

There are differences depending on the level of the school stage as to how the curriculum determines the development of the visual-plastic creativity of the students in the secondary education stage, meaning that secondary school subjects consider more than high school subjects that the curriculum determines the development of visual-plastic creativity of pupils in the secondary schooling stage.

To verify this hypothesis, we applied the $t$ test for 2 independent samples. Based on statistical analyzes, we found that there are statistically significant differences $[\mathrm{t}(68)=0.561, p=0.03$ ] between the averages. Thus, participants who have gained didactic experience only at gymnasium level (3.7 average) considered more than the subjects who have gained high-school experience that the secondary school curriculum (3.6 average) facilitates the development of visual-plastic creativity.

Sub hypothesis No. 3 (b).

There are differences depending on the level of the school stage regarding the way in which the curriculum determines the development of visual-plastic creativity at highschool stage, in the sense that high school level subjects consider more than secondary school subjects that the curriculum determines the development of visual-plastic creativity in high school students.

To verify this hypothesis, we applied the $t$ test for two independent samples. Based on statistical analysis, we found that there were statistically significant differences [ $\mathrm{t}(68)=3.45, p=0.000$ ] between averages. Thus, participants who have gained high-school level didactic experience (average 1.89) considered more than the participants who gained only secondary school experience $(3.35$ average) that high school curriculum facilitates the development of visual-plastic creativity.

Hypothesis No. 4. Opinion on curricular orientation according to the learning cycle.

There is an association between the opinion on curricular orientation and the 
learning phase, meaning that subjects who consider the curriculum to be rather modern at the high school stage, also consider that secondary school level curriculum is rather modern as well.

In order to verify this hypothesis, we applied the $\chi^{2}$ test for independent samples. On the basis of statistical analyzes, we found that there is a statistically significant association at the $p=0.000$ threshold between the opinion of the curriculum orientation as being rather modern and the orientation of the curriculum as being rather postmodern and the stages of secondary and lyceum learning $\left[\chi^{2}\right.$ $=13.32, \mathrm{DF}=1, p=0.000$ ] between averages. There are 47 participants who provided answers on the high-school learning cycle. Of these, 31 considered both high school and secondary school curriculum to be rather modern; 16 subjects considered the high school curriculum rather contemporary, of the 16 subjects, 10 considered the curriculum from secondary-school to be modern, and the remaining 6 subjects considered the secondary school curriculum to be contemporary. Participants who considered the high school curriculum to be rather modern also considered the seondary school curriculum to be rather modern.

Hypothesis No. 5. Using contemporary examples at a formal level, depending on the learning cycle.

There are differences according to the learning stage in terms of the opinion that, at a formal level, it is permissible to use contemporary examples, in the sense that the subjects consider that, formally, at the secondary-school level the school curriculum facilitates the use of examples from contemporary art to a greater extent than to the high school stage.

To verify this hypothesis, we applied the $t$ test for two pair samples. Based on statistical analyzes, we found that there are statistically significant differences [ $\mathrm{t}$ $(68)=4.32, p=0.000]$ between the averages. Thus, according to the obtained results, the experimental group considered that, in terms of secondary school learning cycle (average 3.23), at a formal level, the curriculum facilitates the use of examples from contemporary art to a greater extent than at the of high school education cycle (average 2.30).

Hypothesis No. 6. Use of contemporary examples at a formal level depending on curricular orientation.

There are differences depending on the perception of curricular orientation regarding the opinion that, at the formal level, it is allowed to use contemporary examples at the secondary schooling stage, in the sense that the subjects who perceive the curricular orientation from secondary school as rather modern are of the opinion that, at a formal level, the curriculum facilitates less the use of examples from contemporary art in the secondary schooling stage.

To verify this hypothesis, we applied the $t$ test for two independent samples. Based on statistical analyzes, we found that there are statistically significant differences $[\mathrm{t}(68)=3.20, p=0.002]$ between the averages. Thus, according to the obtained results, the participants who perceived the curricular orientation from secondary school as rather modern (the average 3.10 ) considered that, at the 
formal level, the curriculum facilitates less the use of examples from contemporary art, while the participants that perceived the secondary school curriculum as being rather contemporary (the average 3.90) considered that, at a formal level, the use of contemporary examples is facilitated.

Hypothesis No. 7. The use of contemporary examples at formal level according to the professional status.

There are significant differences based on the professional status with regard to the view that, at a formal level, it is allowed to use contemporary examples at the secondary education stage, in the sense that teachers consider more than the students that, formally, school curriculum facilitates the use of contemporary examples at the high school stage.

To verify this hypothesis, we applied the $t$ test for two independent samples. Based on statistical analyzes, we found that there are statistically significant differences [ $\mathrm{t}(47)=1.09, p=0.04]$. Thus, teachers (3.44 average) considered more than students (3.22 average) that, at a formal level, it is easier to use contemporary examples in plastic education classes during the high school cycle.

Hypothesis No. 8. Visual-plastic creativity development through examples of contemporary art according to the learning cycle.

There are differences between the learning stages, in terms of the opinion on the development of visual-plastic creativity through examples of contemporary art, in the sense that the subjects consider to a greater extent that during the secondary education stage visual-plastic creativity develops through contemporary art examples rather than at the high-school stage.

To verify this hypothesis, we applied the $t$ test for two pair samples. Based on the statistical analyzes, we found that statistically significant differences [ $\mathrm{t}(68)=$ 4.07, $p=0.000$ ] between the averages. Thus, according to the obtained results, subjects considered that the use of examples inspired by contemporary art during plastic art classes could develop plastic visual creativity to a higher degree among the students in the gymnasium (3.85 average) than in high school students (2.83 average).

Hypothesis No. 9. General creativity development through examples of contemporary art according to the learning cycle

There are differences between the learning stages in terms of the general development of creativity through examples of contemporary art, meaning that subjects consider to a greater extent that general creativity develops through examples of contemporary art during secondary school learning rather than during the high school stage.

To verify this hypothesis, we applied the $t$ test for two pair samples. Based on the statistical analyzes, we found that there are statistically significant differences [ $\mathrm{t}(68)=5.005, p=0.000]$ between the averages. According to the obtained results, the subjects considered that the use of contemporary art inspired examples during plastic education classes could further develop general creativity among secondary school students (4.02 average) than among high school students (2.75 
average).

Hypothesis No. 10. Development of visual-plastic and general creativity through examples of contemporary art during high school according to the school profile.

There are differences based on the school profile regarding the opinion on the development of visual plastic creativity through examples from contemporary art of high-school students and the opinion on the development of general creativity through examples from contemporary art of high-school students, meaning that subjects from a vocational profile consider more than the subjects from a theoretical profile that visual-plastic creativity and general creativity can be developed by using examples from contemporary art during the high school stage.

To verify this hypothesis, we applied the $t$ test for independent samples. Based on statistical analyzes, we found that there are statistically significant differences on the $p=0.000$ threshold between subjects who have gained experience in vocational education institutions and those who have gained experience in the theoretical education institutions regarding the opinion on the development of plastic visual creativity $[\mathrm{t}(68)=1.19, p=0.000]$, as well as the opinion on the development of general creativity through examples from contemporary art of students at high-school [ $\mathrm{t}(68)=1.97, p=0.000] \mathrm{cf}$.

Subjects who have gained experience in vocational school establishments considered to a greater extent that high school students' visual-plastic creativity and general creativity can be developed by using examples of contemporary art than the subjects who worked or who have accumulated didactic experience in institutions with a theoretical profile.

Hypothesis No. 11. Development of visual-plastic and general creativity through examples of contemporary art at high school depending on the level of the school cycle.

There are differences depending on the level of the school stage regarding the opinion on the development of plastic visual creativity through examples from contemporary art and the opinion on the development of general creativity through examples from contemporary art of high-school students, meaning that high-school subjects consider more than secondary-school subjects that visual-plastic creativity and general creativity can be developed by using examples from contemporary art to the high-school learning stage.

To verify this hypothesis, we applied the $t$ test for independent samples. On the basis of statistical analyzes, we found that there are statistically significant differences on the $\mathrm{p}=0.000$ threshold among the subjects who have gained secondary-school didactic experience and the subjects who have gained high-school level experience regarding the opinion on the development of visual plastic creativity through examples from contemporary art $[\mathrm{t}(68)=2.89, p=0.000]$, as well as the opinion on the development of general creativity through examples of the contemporary art of high school students, [t $(68)=3.94, p=0.000]$, cf. 
Subjects who have gained high-school level experience have considered to a greater extent that high school students' visual-plastic creativity and general creativity can be developed by using examples from the contemporary art than those who have gained secondary-school level experience.

Analysing the results presented above as well as some other statistically significant results, of correlative type, we can summarize that the general opinion on the school curriculum was that it develops visual creativity, but the curriculum was perceived as oriented towards modern art and not very flexible in approaching contemporary art (only a small number of teachers have considered this). At the same time, the teacher's perceptions of school curriculum are very important. Thus, the small number of teachers who considered that the school curriculum for high school was open to contemporary art were of the opinion that the use of examples from contemporary art develops the visual creativity and general creativity of pupils during secondary school and high-school.

\section{Conclusion}

In general, it is considered that the current school curricula of the Plastic Education discipline develop visual creativity more in the case of secondary-school students than the programs related to the high-school learning cycle. This may due to the fact that in secondary school the Plastic Education discipline is studied for four years, and in high school only the Human, Theological and Pedagogical profiles study Plastic Education, Visual Education and Artistic Education for four years (citation). For the rest, it is studied only for the first two years of high school (9th and 10th grade, for Science, Sport, Military, and the Choreography and Actor's Art artistic profiles). In this respect, in order to balance the ratio between high school and secondary school level, in educational institutions where this situation is identified, non-formal artistic activities can be conceived and proposed, such as: artistic creation circles, activities such as artistic experiments, museum and contemporary art galleries visits (Clement, 1993).

Teachers from vocational institutions considered, to a greater extent than those who gained theoretical experience, that the school curriculum develops pupils' visual creativity both in secondary-school and in high school. Perhaps their opinion is reinforced by the specific characteristics of vocational art education: four years of plastic art education at secondary-school, seven hours a week, and four years of high school artistic education, between 11 - 13 hours a week, these hours being divided into specialized artistic disciplines: the study of color, drawing, composition, history and art theory, etc., depending on the specialization. In this sense, it could go two ways: conceiving educational policies aimed at modifying the curricula developed by the ministry in order to improve the visualization and the development of visual creativity in a higher percentage; developing training programs for teachers in institutions with a theoretical profile to allow for a greater adaptation of the curriculum content according to the real development needs of students (Ciolan, 2002). 
Participants who have gained experience only at secondary-school level have found that the school curriculum develops visual creativity more during secondary school than during high school, while those who have gained high-school level experience have been of the opinion that the school curriculum develops visual creativity more during high school than during secondary school. We believe that the views of the subjects are largely influenced by the school level at which they have gained most experience. In this sense, discussion sessions could be organized so that teachers could benefit from experience exchanges and good practice ideas sharing, starting from their didactic experience at secondary and high school level (Aprotosoaie, 2014).

In general, the participants considered the curriculum, both from secondary-school and high school, as being oriented rather towards the language of modern art. Teachers, more than the students, agreed on this topic. We believe that students have had a more open opinion than teachers did from this point of view, and this may be due to pedagogical practice experience and to didactic courses advocating for curricular flexibility. Their open attitude may be due to the fact that they have not entered the education system in order to understand, to feel and to apply all the formal rigors. In this respect, continuous training programs for experienced teachers can be organized by the university, where the issue of the necessity to approach the language of contemporary art during the didactic practice should be discussed, in order to form a public that can process the forms of manifestation to contemporary art (Addison \& Burgess, 2007).

Most participants considered the secondary school curriculum to be modern art oriented. Only 6 participants (out of a total of 68 participants) considered both curricula (secondary school and high-school) to be open to approach the language of contemporary art. Considering that secondary-education curriculum really addresses modern art language, the responses of the 6 subjects show that they have a very flexible and open approach to school curriculum, making reference often or very often to contemporary art in addressing formally imposed content. In order to form a future public that understands the language of contemporary art, it is necessary to go through the modern art language first but, as a preliminary step, modern techniques of contemporary expression may be approached in the didactic practice during secondary school using the modern art language. Therefore, teacher training strategies can be considered for the development of this proposal (Aprotosoaie, 2016).

Participants who considered the curriculum to be oriented towards a modern language may be less open and flexible to approach a contemporary language in their teaching activities and they prefer to comply with a large extent to the formal curriculum norms. However, there were also participants who considered the secondary and high-school curricula to be modern-oriented, and who were, thus, open to addressing contemporary language in their didactic activities and therefore to adopt a more open curricular approach, a more flexible one. In this respect, strategies for making the curriculum more flexible can be proposed to the relevant ministry. 
There are also high school teachers with an open attitude to the assumption of contemporary language. However, it should not be forgotten that in general the curriculum was perceived as being oriented towards a modern language, and the openness of teachers to the approach of a contemporary language beyond the formal frameworks was rather limited.

Regarding the beginner teachers, we can conclude that: they preferred contemporary art, they were more open to organizing didactic activities, more flexible to approach the curriculum differently, they have more didactic openness, they do not feel the pressure of formal rigors so much. Regarding the experienced teachers, we can conclude that: they identify themselves as being more modern artists, more in line with the formal rules of curricular approach to school curricula; they tend to get less out of the lines; they do not have the same mood to improvise; as artists, they prefer the language of modern art more, and therefore, may think that students' competences can be sufficiently developed by using modern language; they do not consider it necessary to use contemporary language. The implications of this may concern two aspects: the new generation of visual arts teachers comes with a new openness from contemporary artistic practices, which will have an impact on students-the next generation of art consumers; it is necessary to develop educational policies that will follow the exchange of experience and good practices between the two categories of teachers-experienced and debutants-in order to increase the educational act in the artistic field.

In this study, teachers considered that the use of contemporary examples develops visual creativity and general creativity more in secondary school students than in high school students. The majority of the participants gained secondary-school level experience, so one can deduct that the profile of the school institution and the school level at which the subjects were formed during the teaching career mark the expressed beliefs.

New teachers preferred contemporary art. They considered to a greater extent that the general creativity of high school students can be developed by using contemporary examples during didactic activities. Concerning this conclusion, it should be noted that most of the debutant teachers have gained secondary-school experience ( 8 first-time teachers out of 11). It is a positive aspect the fact that they considered that general creativity of high school students could be developed, so they showed openness to contemporary art; they realized the advantages of including the contents and examples of contemporary art in the didactic activities. Asking ourselves why early-stage teachers did not think this and about secondary-school as well, we can answer keeping in mind the analysis of the the curriculum documents, which reveals that indeed high school curriculum allows to a higher degree than secondary school curriculum an approach to contemporary art in terms of content and learning activities. Thus, the new teachers comply with the formal rigors of the secondary school curriculum, but they objectively perceive the degree of openness and flexibility of the curriculum, addressing it in a flexible and personalized manner. 
The present study has achieved its objective insofar as it: provided indicative data on the extent to which pre-university art education in Iasi is open to the new forms of visual expression of contemporary art; has provided ideas for the renewal of pre-university educational practices by addressing the activities to support examples of contemporary art; offered ideas for improving educational practices at university level in order to train teachers with a flexible vision in the curricular approach of educational and artistic activities; it offered ideas in the direction of proposing more flexible educational policies for the current art curriculum, it offered ideas for the development of continuous training programs for the teachers involved in the educational system, for the flexibility of the didactic activity.

The limits of the study were given by the fact that: the research was carried out on a small number of participants, the experimental group was formed by both active didactic staff and under-trainning teachers-students-their opinion influencing the accuracy of the results; the results can only be reported at a local level, most of the respondents who answered the questionnaire were from Iaşi and only a few from Iaşi County or other cities, thus preventing us from generalizing the results at a regional or national level.

As future research directions, we aim at refining the working tool (the questionnaire) and carrying out more extensive research involving a larger number of participants from several counties and cities.

The research aims to reinforce the conclusions reached at an intuitive level as a result of the Contemporary art for young people mediation project, namely: the degree of openness of pre-university teachers to contemporary art is not always manifested during didactic activities, although young people may be more interested in new forms of contemporary art, than in traditional ones, in the context of translating contemporary language to their level of understanding (this can be done through mediation activities). This leads us to develop work manners that could facilitate the didactic approach in order to integrate contemporary visual language into the educational process.

\section{Conflicts of Interest}

The author declares no conflicts of interest regarding the publication of this paper.

\section{References}

Addison, N., \& Burgess, L. (2007). Learning to Teach Art and Design in the Secondary School. A Companion to School Experience (2nd ed.). London and New York: Routledge Taylor \& Francis Group. https://doi.org/10.4324/9780203962466

Adorno, T. W. (1998). Aesthetic Theory. Minneapolis, Minnesota, MN: University of Minnesota Press.

Aprotosoaie, A. M. (2014). Nevoia de educație prin și pentru artă. Proceedings of The Moldavian Science Academy, the Education Science Institute, Chișinău, 134-139.

Aprotosoaie, A. M. (2016). The Openness of the Visual Art Curriculum towards a New 
Visual Art Language. Review of Artistic Education, 11-12, 175-182.

https://doi.org/10.1515/rae-2016-0021

Babias, M., \& Nollert, A. (2007). Periferic 7. Focussing Iași/Social Processes. International Biennial for Contemporary Art. Iași: Polirom and Revolver Publishing House.

Bamford, A. (2006). The WOW Factor: Global Research Compedium on the Impact of the Arts in Education. Germany: Waxmann Verlag GmbH.

Bartos, J. (2005). Structuri compoziționale. Iaşi: Artes Publishing House.

Bartos, J. (2006). Arta murală. Interferențe vizual artistice. Iași: Artes Publishing House.

Ciolan, L. (2002). Reforma curriculară în învățământul liceal românesc, premise, politici, metodologii. In E. Păun, \& D. Potolea (coord.), Pedagogie. Fundamentări teoretice şi demersuri aplicative (pp. 120-145). Iaşi: Editura Polirom.

Clement, R. T. (1993). The Art Teacher's Handbook (2nd ed.). London: Stanley Thornes (Publishers) Ltd.

Greenberg, C. (1982). Modernist Painting. In F. Frascina, \& C. Harrison (Eds.), Modern Art and Modernism. A Critical Anthology (pp. 5-10). New York: Harper \& Row. https://doi.org/10.4324/9780429498909-2

Kennick, W. (Ed.) (1979). Art and Philosophy: Readings in Aesthetics. New York: St. Martin's Press.

Levinson, J. (2003). The Oxford Handbook of Aesthetics. Oxford: Oxford University Press.

Onofrei, G. (2008a). Răspunsul bienalei "Periferic 8" la criza mondială: Arta ca dar. Article in the on-line magazine Suplimentul de cultură. NR. 200, 11-17 octombrie 2008, Săptămânal realizat de Editura Polirom și “Ziarul de Iași”. http://suplimentuldecultura.ro/numarpdf/200_Iasi.pdf

Onofrei, G. (2008b). Periferic 8: Arta ca dar. Suplimentul de Cultură, No. 165, 9-2-2008. http://suplimentuldecultura.ro/2907/periferic-8-arta-ca-dar/

Osten, M., Spilmann, P., Swieckowska, T., \& Szreder, K. (2009). Knowledge-Based Economy and Its Losers. În Idea. Artă + Societate, Number \#33-34, pp. 105-111. http://idea.ro/revista/?q=ro/node/40\&articol=617

Vica, C. (2008). Răspunsul "Periferic 8" la criza mondiala: Arta ca dar. Suplimentul de cultură, No. 200, 11-10-2008.

http://suplimentuldecultura.ro/4089/raspunsul-periferic-8-la-criza-mondiala/

Wollheim, R. (1980). Art and Its Objects. New York: Cambridge University Press. https://doi.org/10.1017/CBO9781316286777

Zaharia, D. N. (1999). Antinomicul în arta contemporană. Iași: Editura Dosoftei. 